\title{
EFEITO DOS MEIOS DILUIIDORES MMC (MÍNIMA CONTAMINAÇÃO) E LGM (LACTOSE-GEMA MODIFICADO) NA VIABILIDADE DO SÊMEN DE CÃES CONSERVADO POR 24 HORAS EM EQUITAINER ${ }^{\circledR}$.
}

\author{
Bianca Perez Barcellos, ${ }^{1}$ Marco Antônio Rocha, ${ }^{1}$ Luciano Jamas, ${ }^{2}$ Felipe Zandonadi Brandão, ${ }^{3}$ \\ Luis Garcia Nogueira ${ }^{3}$ e Tania Goes de Pinho 3 \\ 1. Pós-graduados pela Universidade Federal Fluminense (UFF) \\ 2. Polícia Militar do Rio de Janeiro \\ 3. Professores adjuntos do Departamento de Patologia e Clínica Veterinária, \\ Fisiopatologia da Reprodução (UFF).
}

RESUMO

Objetivou-se com este estudo comparar a viabilidade do sêmen de cães diluído nos meios Mínima Contaminação (MMC) e Lactose-gema Modificado (LGM), conservado a $4{ }^{\circ} \mathrm{C}$ por doze e 24 horas. Foram utilizados treze ejaculados de cinco cães adultos, obtidos através de manipulação digital. Avaliaram-se volume do ejaculado, concentração espermática, motilidade progressiva e vigor espermático no sêmen fresco imediatamente após a coleta. A seguir o sêmen foi diluído (1:3) em MMC e LGM e posteriormente refrigerado em Equitainer ${ }^{\circledR}$. Motilidade progressiva e vigor espermáticos, patologia espermática, integridade da membrana plasmática, viabilidade espermática e integridade acrossômica foram avaliados no sêmen fresco e após doze e 24 horas de refrigeração a $4{ }^{\circ} \mathrm{C}$. Não houve diferença entre os meios na conservação

PALAVRAS-CHAVES: Refrigeração, espermatozoides, caninos. do sêmen após doze horas de refrigeração. Decorridas 24 horas, apenas a motilidade progressiva foi diferente entre os tratamentos ( $\mathrm{p}>0,05)$. Porém, observou-se, que o meio LGM manteve, após esses períodos, a maioria das características do sêmen fresco $(\mathrm{p}>0,05)$. As taxas médias de reação acrossômica verdadeira e falsa não ultrapassaram $2 \%$ em ambos os meios, o que demonstra que a $4{ }^{\circ} \mathrm{C}$ os componentes dos meios diluídores e a conservação não afetaram a integridade acrossômica. Concluiu-se que ambos os meios podem ser utilizados na conservação sob refrigeração (4 ${ }^{\circ} \mathrm{C}$ em contêiner de transporte) do sêmen de cães por um período de até doze horas, sem que ocorram mudanças significativas nas características verificadas no sêmen fresco.

\section{ABSTRACT}

\section{EFECT OF MINIMUM CONTAMINATION MEDIUM (MMC) AND MODIFIED EGG YOLK LACTOSE (LGM) EXTENDERS ON CANINE SEMEN VIABILITY AFTER COOLING AT $4{ }^{\circ} \mathrm{C}$ FOR 24 HOURS IN EQUITAINER®}

The aim of this study was to compare the viability of canine semen after dilution in Minimum Contamination Medium (MMC) and Modified Lactose-Egg yolk extender (LGM) and incubation at $4{ }^{\circ} \mathrm{C}$ for 12 and 24 hours. Thirteen ejaculates were collected from 5 adult dogs by digital manipulation. Macroscopic and microscopic characteristics were assessed right after collection. Semen was divided to be diluted (1:3) in MMC and LGM and subsequently chilled in Equitainer ${ }^{\circledR}$. Seminal parameters of motility and spermatic morphology, membrane integrity (hyposmotic test), spermatic viability and spontaneous acrosome reaction (Trypan-blue Giemsa stain) were evaluated in fresh and chilled semen after 12 and 24 hours of incubation at $4{ }^{\circ} \mathrm{C}$. No difference between extenders was identified in semen conservation after 12 hours. After 24 hours just spermatic motility was different $(\mathrm{p}>0.05)$. But, after both periods of conservation, semen diluted in LGM maintained most of the characteristics verified in the fresh semen. The mean of true and false acrosome reaction did not exceed $2 \%$ in both semen extenders, which demonstrates no influence of media component 
and incubation period on these phenomena at $4{ }^{\circ} \mathrm{C}$. In conclusion, these results indicate that both extenders can be used in canine

KEYWORDS: Dogs, sperm, cooling.

\section{INTRODUÇÃO}

A utilização do sêmen resfriado na inseminação artificial (IA) na espécie canina vem aumentando potencialmente. $\mathrm{O}$ resfriamento do sêmen visa à conservação por um maior período, viabilizando o seu transporte. Durante o processo de resfriamento, ocorre a redução do metabolismo das células espermáticas, de forma a restringir perdas de energia e a diminuir a formação de metabólitos tóxicos no armazenamento e transporte (AMANN \& PICKETT, 1987; HOLT, 2000). O resfriamento do sêmen é um complexo processo que envolve modificações estruturais na célula espermática, podendo provocar lesões irreversíveis no espermatozoide. Ocorrem alterações na fluidez da membrana plasmática e no influxo de cálcio na célula, culminando com a ruptura das membranas plasmática e acrossomal. Essas alterações são conhecidas como choque térmico (TARTAGLIONE \& RITTA, 2004).

O sucesso da conservação do sêmen sob refrigeração está na dependência de fatores, como o uso do diluídor adequado, cujos componentes protejam os espermatozoides contra o choque térmico e não permitam a ocorrência da capacitação espermática precoce, da taxa de resfriamento lenta e da temperatura de manutenção, minimizando os danos na membrana e no metabolismo da célula espermática (AMANN \& GRAHAN,1993). Os meios diluídores mais utilizados na conservação do sêmen são aqueles que possuem macromoléculas presentes no leite e/ou na gema de ovo, que são protetoras da membrana celular (HOLT, 2000).

A gema de ovo contém lecitina, o componente de origem biológica mais utilizado na composição dos diluídores para sêmen (ENGLAND, 1993). Sua ação protetora contra os efeitos prejudiciais do resfriamento celular parece advir de uma ação estabilizadora da membrana espermática através de seus componentes fosfolipídicos, os quais atuam na restauração da perda de fosfolipídios celulares e na prevenção contra rupturas das membranas (ROTA et al., 1995; HOLT, 2000). PHILLIPS \& LARDY (1993) observaram que as lipoproteínas presentes na gema de ovo promovem semen conservation at $4{ }^{\circ} \mathrm{C}$ in contêiner during 12 hours without significant changes in semen characteristics.

a proteção dos espermatozoides contra o choque térmico provocado pelo resfriamento (MAXWEEL \& SALOMON, 1993).

Uma lipoproteína de baixa densidade (LDL) foi previamente isolada e identificada como componente efetivo na preservação e proteção do espermatozoide. De acordo com vários autores, há melhor motilidade espermática com meios contendo maior quantidade de LDL (MOUSSA et al., 2002; AMIRAT et al., 2004).

O leite é também bastante utilizado, devido à sua capacidade tampão e à ação protetora contra o choque térmico exercida pela lactose e pelas proteínas que o compõem. O meio diluente à base de leite desnatado e glicose utilizado para resfriamento de sêmen equino tem sido utilizado com sucesso no resfriamento de sêmen canino (ENGLAND \& PONZIO, 1996).

Os meios MMC, Tris-gema e LGM vêm sendo testados e utilizados no resfriamento de sêmen de cães (IVANOVA-KICHEVA et al., 1997; CUNHA \& LOPES, 2000; SILVA et al., 2001), sendo que IVANOVA-KICHEVA et al. (1997) relataram ligeira superioridade do LGM na conservação das características seminais estudadas.

Para avaliar a qualidade do sêmen conservado, têm-se utilizado diversos testes; porém, há um consenso de que não existe um único teste in vitro que possa predizer com exatidão o potencial de fertilidade do sêmen fresco ou conservado (ARRUDA et al., 2003).

Os parâmetros seminais como motilidade progressiva, vigor espermático, morfologia espermática, integridade de membrana plasmática e avaliação da integridade acrossomal têm sido indicados na avaliação do sêmen de diversas espécies domésticas (CUNHA et al., 2005). A motilidade progressiva e o vigor espermático refletem indiretamente a capacidade fertilizante do espermatozoide (VANNUCCHI et al., 1998). A integridade das membranas plasmática e acrossômica, verificada no teste hiposmótico e na coloração para avaliação da capacitação espermática através da reação acrossômica, também é parâmetro para medir a capacidade do espermatozoide de penetrar o oócito (JEYENDRAN et al., 1984). Já os métodos de 
coloração vital ajudam a determinar o percentual de espermatozoides vivos no sêmen (DIDION et al.,1989).

Sendo assim, objetivou-se com este estudo verificar a viabilidade espermática após a diluição nos meios comumente utilizados na conservação do sêmen de cães (MMC e LGM), após doze e 24 horas sob refrigeração $\left(4^{\circ} \mathrm{C}\right)$. Compararam-se a motilidade progressiva, o vigor, o percentual de células vivas e a integridade das membranas plasmática e acrossomal.

\section{MATERIAL E MÉTODOS}

Foram utilizados treze ejaculados de cinco cães (três coletas em três cães e duas coletas em dois cães) adultos (de três a seis anos de idade), hígidos, das raças Pastor alemão, Beagle com pesos entre 15 e $40 \mathrm{~kg}$ e provenientes do canil da polícia militar. Alimentaram-se os animais com ração comercial (Champ ${ }^{\circledR}$ ), duas vezes ao dia, e água ad libitum. Após a realização de exame andrológico e esgotamento das reservas espermáticas, o sêmen de cada animal foi coletado em intervalos de sete dias, durante a primavera, através de manipulação digital, sendo utilizadas apenas a segunda fração espermática e parte da terceira fração seminal (de um a dois primeiros jatos da ejaculação clara e límpida).

O ejaculado foi imediatamente avaliado quanto ao volume, concentração espermática, motilidade progressiva e vigor espermáticos, patologia espermática, integridade de membrana plasmática, viabilidade espermática e integridade da membrana acrossômica, sendo mantido em banho-maria a $37{ }^{\circ} \mathrm{C}$ até o procedimento da diluição. Os padrões mínimos do sêmen fresco para sofrer posterior diluição foram: $70 \%$ de motilidade progressiva e vigor 3 .

Os ejaculados foram divididos em partes iguais e diluídos lentamente (taxa de diluição 1:3) em Meio Mínima Contaminação (KENNEY et al., 1975) e Lactose-gema Modificado (SILVA FILHO et al., 1997). Após a diluição, as amostras foram acondicionadas em tubos plásticos de $1,5 \mathrm{~mL}$ para o armazenamento.

$\mathrm{Na}$ refrigeração e manutenção do sêmen a $4{ }^{\circ} \mathrm{C}$ durante 24 horas foi utilizado contêiner de transporte comercial (Equitainer $\mathrm{II}^{\circledR}$ ) que apresenta curva de temperatura em declínio de $37^{\circ} \mathrm{C}$ a $5{ }^{\circ} \mathrm{C}$ em dez horas (declínio médio de $0,3{ }^{\circ} \mathrm{C}$ por minuto).

Os parâmetros seminais de motilidade progressiva e vigor espermáticos, patologia espermática, inte- gridade de membrana plasmática do espermatozoide, viabilidade espermática e integridade do acrossoma foram novamente avaliados no sêmen refrigerado após doze e 24 horas. Antes da reavaliação do sêmen, alíquotas das amostras foram pré-aquecidas.

Testes realizados

A concentração espermática foi determinada utilizando-se câmara hematocitométrica (Neubauer) em microscópio óptico com aumento de $400 \mathrm{x}$, sendo utilizadas amostras de sêmen na diluição 1:20.

Avaliaram-se a motilidade progressiva e o vigor espermáticos subjetivamente, em microscopia óptica comum, sendo a motilidade determinada como a porcentagem de espermatozoides com movimento retilíneo progressivo, e o vigor classificado numa escala de 0 a 5, de acordo com a intensidade do movimento observado (HENRY \& NEVES,1998).

A patologia espermática foi avaliada através de preparação úmida, utilizando-se microscópio de contraste de fase em aumento de 1.000x, em imersão, em duzentas células. Determinaram-se os percentuais de defeitos maiores, menores e totais (BLOM, 1973).

A integridade da membrana plasmática foi determinada através do teste hiposmótico (KUMI-DIAKA, 1993). Uma alíquota de $50 \mu \mathrm{L}$ de sêmen foi diluída em $450 \mu \mathrm{L}$ de solução hiposmótica $150 \mathrm{mosmol} / \mathrm{L}$ (taxa de diluição 1:10) previamente aquecida a $37^{\circ} \mathrm{C}$, sendo a seguir incubada por trinta minutos em banho-maria a $37^{\circ} \mathrm{C}$. Após a incubação, uma gota da amostra foi colocada entre a lâmina e a lamínula, aquecidas a 37 ${ }^{\circ} \mathrm{C}$, e foi avaliada em microscopia óptica com aumento de 400x para contagem de cem células. O resultado foi expresso em porcentagem de células íntegras (que apresentaram dobramento de cauda por alterações de osmolaridade).

A avaliação da viabilidade espermática e da integridade do acrossomo foi realizada pela técnica citoquímica de coloração dupla Trypan-blue Giemsa (DIDION et al., 1989). Uma alíquota de $100 \mu \mathrm{L}$ de sêmen foi diluída em $100 \mu \mathrm{L}$ de azul de Tripan $0,2 \%$, previamente aquecido a $37^{\circ} \mathrm{C}$. A amostra foi incubada por trinta minutos em banho-maria a $37^{\circ} \mathrm{C}$. Após a incubação, uma gota de sêmen foi colocada sobre cada lâmina previamente aquecida a $37{ }^{\circ} \mathrm{C}$ em placa aquecedora, para a confecção de esfregaços finos secos ao 
ar. Incubaram-se essas lâminas em solução de Giemsa $10 \%$ com água destilada $\mathrm{pH} 6.8-6.9$, por 24 horas. Os esfregaços foram lavados em água corrente e secos ao ar. A leitura das lâminas foi realizada através da contagem de cem células em microscópio óptico com aumento de 400x. Essa técnica possibilitou a diferenciação de quatro classes diferentes de espermatozóides: (sptz) mortos com acrossoma intacto - cabeça azul e acrossoma rosado; sptz morto com acrossoma reagido (falsa reação acrossômica) - cabeça azul ou roxa com acrossoma descorado (ausente); sptz vivo com acrossoma intacto (viável) - cabeça rosada ou branca com acrossoma rosado; sptz vivo com acrossoma reagido (verdadeira reação acrossômica) - cabeça rosada ou branca e acrossoma descorado.

$\mathrm{Na}$ análise estatística, avaliaram-se todas as características seminais em relação ao tipo de meio e tempo de conservação. Os dados observados foram submetidos à análise de variância (ANOVA) e as médias foram comparadas pelo teste SNK (Student-
-Newman-Keuls), utilizando-se o Software GraphPad Instat 3.0532 bit for Win 95/NT. O mesmo sistema estatístico foi usado na obtenção das médias e desvios padrão. As diferenças foram consideradas significativas quando $p<0,05$.

\section{RESULTADOS E DISCUSSÃO}

O volume e concentração espermática médios verificados nos ejaculados dos cães foram $3,08( \pm 0,08)$ $\mathrm{mL} \mathrm{e} \mathrm{496,92}( \pm 304,92) \times 10^{6} \mathrm{sptz} / \mathrm{mL}$, respectivamente. Não houve variação do volume do ejaculado entre cães, uma vez que a metodologia adotada preconizou a coleta somente da fração espermática e parte da terceira fração, com o intuito de padronizar o volume para posterior diluição. Observaram-se variações ( $\mathrm{p}<$ $0,05)$ na concentração espermática entre os animais. Variações individuais foram relatadas por ENGLAND \& PONZIO (1996), que observaram concentrações entre $400 \times 10^{6}$ e $900 \times 10^{6} \mathrm{sptz} / \mathrm{mL}$.

TABELA 1. Médias \pm SD das características do sêmen fresco de cães, do sêmen diluído em Meio de Mínima Contaminação (MMC) e em Meio Lactose-gema Modificado (LGM) após doze e 24 horas de refrigeração $\left(4^{\circ} \mathrm{C}\right)$ em Equitainer ${ }^{\circledR}$

\begin{tabular}{|c|c|c|c|c|c|}
\hline \multirow{2}{*}{$\begin{array}{l}\text { Características } \\
\text { seminais }\end{array}$} & \multirow{2}{*}{$\begin{array}{l}\text { Sêmen fresco } \\
\qquad(\mathrm{n}=13)\end{array}$} & \multicolumn{2}{|c|}{$\begin{array}{l}\text { Sêmen diluído em MMC } \\
\qquad(\mathrm{n}=13)\end{array}$} & \multicolumn{2}{|c|}{$\begin{array}{l}\text { Sêmen diluído em LGM } \\
\qquad(\mathrm{n}=13)\end{array}$} \\
\hline & & $\begin{array}{l}\text { doze horas de } \\
\text { refrigeração }\end{array}$ & $\begin{array}{l}24 \text { horas de } \\
\text { refrigeração }\end{array}$ & $\begin{array}{l}\text { doze horas de } \\
\text { refrigeração }\end{array}$ & $\begin{array}{l}24 \text { horas de } \\
\text { refrigeração }\end{array}$ \\
\hline MP (\%) & $89,61( \pm 4,77)^{\mathrm{a}}$ & $51,15( \pm 26,00)^{b}$ & $28,08( \pm 26,34)^{b}$ & $70,00( \pm 12,74)^{\mathrm{ab}}$ & $56,54\left( \pm 27,80^{c}\right)$ \\
\hline $\mathrm{V}(1-5)$ & $4,80( \pm 0,38)^{\mathrm{a}}$ & $2,85( \pm 0,85)^{\mathrm{b}}$ & $1,85( \pm 1,39)^{\mathrm{b}}$ & $3,46( \pm 0,70)^{\mathrm{b}}$ & $2,65( \pm 1,31)^{b}$ \\
\hline DT (\%) & $31,84( \pm 5,64)^{\mathrm{a}}$ & $40,66( \pm 12,01)^{\mathrm{a}}$ & $52,15( \pm 16,04)^{b}$ & $36,77( \pm 8,70)^{\mathrm{a}}$ & $44,54( \pm 12,53)^{a b}$ \\
\hline IM (\%) & $86,54( \pm 3,60)^{\mathrm{a}}$ & $70,46( \pm 5,29)^{\mathrm{b}}$ & $62,77( \pm 9,00)^{\mathrm{b}}$ & $77,53( \pm 5,70)^{\mathrm{ab}}$ & $69,85( \pm 17,25)^{b}$ \\
\hline VE $(\%)$ & $92,23( \pm 6,37)^{\mathrm{a}}$ & $81,46( \pm 11,91)^{b}$ & $75,62( \pm 12,50)^{b}$ & $90,30( \pm 7,01)^{\mathrm{ab}}$ & $83,39( \pm 8,48)^{\mathrm{ab}}$ \\
\hline VRA (\%) & $0,38( \pm 1,12)^{\mathrm{a}}$ & $0,31( \pm 1,11)^{\mathrm{a}}$ & $0,31( \pm 0,85)^{\mathrm{a}}$ & $0,15( \pm 0,55)^{\mathrm{a}}$ & $0,31( \pm 0,75)^{\mathrm{a}}$ \\
\hline FRA $(\%)$ & $0,23( \pm 0,60)^{\mathrm{a}}$ & $0,23( \pm 0,60)^{\mathrm{a}}$ & $0,38( \pm 0,77)^{\mathrm{a}}$ & $0,38( \pm 0,96)^{\mathrm{a}}$ & $0,46( \pm 1,13)^{\mathrm{a}}$ \\
\hline
\end{tabular}

Letras diferentes na mesma linha, para cada característica, indicam $\mathrm{p}<0,05$ pelo teste SNK. MP: motilidade progressiva; V: vigor espermático; DT: defeitos totais; IM: integridade de membrana plasmática; VE: viabilidade espermática (sptz vivos com acrossoma intacto); VRA: verdadeira reação acrossômica (sptz vivos com acrossoma reagido); FRA: falsa reação acrossômica (sptz morto com acrossoma reagido).

Nota-se na Tabela 1 que os parâmetros do sêmen fresco encontram-se adequados para a utilização na inseminação artificial (IA) (VERSTEGEN et al., 2005), com exceção da patologia espermática, com média acima do limite $(31,84( \pm 5,64)$, pelo fato de não ter sido um critério de seleção para os ejaculados. A porcentagem média de defeitos maiores e menores foi $22,77( \pm 2,98) \%$ e de $9,08( \pm 4,37) \%$, respectivamente. Os valores de patologia espermática total foram mais elevados dos que aqueles encontrados por 
VERSTEGEN et al. (2005) e RIJSSELAERE et al. (2002). Esses autores verificaram menos do que $15 \%$ de defeitos totais, o que pode ter se devido ao fato de os animais terem uma rotina de exercícios de treinamento de segurança, ocasionando diferentes níveis de estresse (HATAMOTO et al., 2006; BAPTISTA SOBRINHO et al., 2009).

No entanto, as médias de motilidade progressiva (MP) e vigor (V) no sêmen fresco foram elevadas, possivelmente em virtude da prévia seleção dos ejaculados (motilidade progressiva superior a 70\% e vigor mínimo 3). A motilidade progressiva bem como a patologia espermática têm sido utilizadas como parâmetros de seleção de ejaculados que serão armazenados (refrigerados e/ou congelados) pelo fato de terem uma correlação elevada com a resistência ao choque térmico (VERSTEGEN et al., 2005). No entanto, TARTAGLIONE \& RITTA (2004) relataram a superioridade dos parâmetros integridade e funcionalidade de membrana plasmática e integridade de membrana acrossomal em relação à morfologia e motilidade espermáticas na predição da fertilidade do sêmen de touros. Verificou-se que as porcentagens de espermatozoides viáveis e com membranas plasmática e acrossomal íntegras também foram elevadas no sêmen fresco.

Após doze horas de conservação dos ejaculados observa-se melhor conservação das características do sêmen diluído em LGM em relação ao sêmen fresco. $\mathrm{O}$ mesmo não ocorreu naquele diluído em MMC, possivelmente devido à proteção contra o choque térmico dos componentes da gema de ovo do meio LGM (ENGLAND, 1993), cujos fosfolipídicos promovem uma ação estabilizadora da membrana espermática, restaurando-a após a perda de fosfolipídios que ocorre durante o processo de refrigeração, prevenindo as rupturas (ROTA et al., 1995; HOLT, 2000)

Verifica-se na Tabela 1 que não houve diferença significativa entre as características do sêmen fresco e do conservado por doze horas, com exceção do vigor espermático $(p<0,05)$. Embora isso tenha ocorrido, nota-se que o vigor médio foi superior a 3 .

As médias de todas as características do sêmen diluído em LGM após doze horas de conservação encontram-se dentro dos padrões indicados para a IA (CONCANNON \& BATTISTA, 1989; VERSTEGEN et al., 2005), com exceção da patologia espermática $(36,77 \%)$, provavelmente por essa característica já ter sido de 31, $84 \%$ no sêmen fresco. Porém, os dois valores não diferiram significativamente. Os defeitos mais frequentemente observados após a conservação foram os dobramentos de cauda, o pode estar relacionado ao choque térmico (PARKS \& GRAHN, 1992). Já o sêmen diluído em MMC apresentou características inferiores $(p<0,05)$ às do sêmen fresco após doze horas de conservação, com exceção da reação acrossômica e da patologia espermática. Mesmo assim, a maioria das características também se encontra dentro dos padrões para a IA (VERSTEGEN et al., 2005).

Verifica-se que as médias das características do sêmen diluído em LGM após 24 horas de conservação não foram diferentes daquelas verificadas no sêmen conservado por doze horas. Ocorreu um declínio significativo $(\mathrm{p}<0,05)$ apenas da motilidade progressiva, que se manteve, ainda, acima de 50\%. Algumas características, no entanto, diferiram pelas do sêmen fresco.

Observa-se, contudo, no entanto, que após 24 horas os dois diluídores também não diferiram estatisticamente entre si, sendo apenas a motilidade progressiva menor no sêmen conservado em MMC $(56,54( \pm 7.00))$. Verifica-se, ainda, que o sêmen conservado por 24 horas apresenta, em ambos os meios, valores bastante satisfatórios em relação à viabilidade espermática, à integridade de membrana plasmática e à porcentagem de espermatozoides apresentando reação acrossômica.

O número de espermatozoides no sêmen fresco apresentando reação acrossômica (RA) falsa ou verdadeira foi pequeno. De fato, não se espera encontrar no sêmen fresco número expressivo de espermatozoides capacitados e apresentando reação acrossômica (CORMIER et al., 1996). Sabe-se que o tempo, a temperatura e os componentes dos meios diluídores são fatores que podem induzir a reação acrossômica espontânea (SIRIVAIDYAPONG et al., 2000). Porém, as taxas médias de reação acrossômica verdadeira e falsa não ultrapassaram $1 \%$ após a conservação sob refrigeração em ambos os meios, o que demonstra que após 24 horas, a $4{ }^{\circ} \mathrm{C}$, os componentes dos meios diluídores e a conservação não induziram esses fenômenos e impediram danos do acrossoma. IGUER-OUADA \& VERSTEGEN (2001) verificaram também menos de $5 \%$ de reação acrossômica após a diluição do sêmen de cães em meio TRIS Gema e a conservação por 72 horas a $4{ }^{\circ} \mathrm{C}$. 
Tanto a viabilidade espermática (VE) quanto a integridade de membrana plasmática (IM) mantiveram-se relativamente elevadas após 24 horas de conservação nas amostras diluídas em ambos os meios. RIJSSELAERE et al. (2002) observaram em torno de 93\% de espermatozoides vivos apresentando acrossoma intacto, após diluição do sêmen de cães em meio TRIS Gema e conservação por 72 horas a $4{ }^{\circ} \mathrm{C}$.

Apesar de ocorrerem algumas alterações na qualidade do sêmen após a conservação, muitas características mantiveram-se ainda satisfatórias no sêmen diluído em LGM após 24 horas de refrigeração. CUNHA e LOPES (2000) obtiveram 70\% de motilidade progressiva e vigor 5, após 24 horas de conservação do sêmen de cães diluído em Glicina-gema, não diferindo das características do sêmen fresco. VERSTEGEN et al. (2005) também não constataram queda significativa desses parâmetros após 24 horas de conservação em meio TRIS-gema glicose a $4{ }^{\circ} \mathrm{C}$. Em cães, $60 \%$ de espermatozoides com motilidade progressiva e $10 \%$ ou menos apresentando reação acrossômica podem ser considerados bons parâmetros de qualidade seminal após refrigeração (VERSTEGEN et al., 2005). CONCANNON \& BATTISTA (1989) sugeriram que é necessário o mínimo de $40 \%$ a $50 \%$ de MP para o sucesso da IA. Sabe-se que os meios diluídores são de suma importância para minimizar as alterações que ocorrem durante o choque térmico na refrigeração do sêmen, porém, deve-se ressaltar a importância de se terem inicialmente amostras de sêmen de boa qualidade para garantir a conservação mais prolongada das características necessárias para a fecundação.

Reitera-se a importância de inclusão da avaliação da morfologia espermática na seleção de ejaculados, pois a motilidade progressiva nem sempre reflete determinadas condições patológicas dos espermatozoides e viabilidade espermática (CASTRO et al., 2007). Caso houvesse seleção dos animais incluindo a patologia espermática, provavelmente os resultados obtidos após 24 horas de conservação do sêmen pudessem ser mais próximos aos do sêmen fresco.

\section{CONCLUSÃO}

Nas condições deste experimento, conclui-se que ambos os meios diluídores podem ser utilizados na conservação do sêmen de cães por pelo menos doze horas, sob refrigeração a $4{ }^{\circ} \mathrm{C}$, em contêiner de transporte, sem que ocorram intensas mudanças nas características verificadas no sêmen fresco.

\section{AGRADECIMENTO}

Ao $12^{\circ}$ Batalhão da Polícia Militar do Rio de Janeiro, pela fundamental colaboração neste projeto. À Capes pelo apoio concedido.

\section{REFERÊNCIAS}

AMANN, R. P.; GRAHAN, J. K. Spermatozoa function. In: McKINNON, A. O. VOSS, J. L. Equine reproduction, 1993. p. 715-745.

AMANN, R. P.; PICKET, B. W. Principles of cryopreservation and a review of cryopreservation of stallion spermatozoa. Equine Veterinary Science, v. 7, n. 3, p. 145-173, 1987.

AMIRAT, L.; TAINTURIER, D.; JEANNEAU, L.; THORIN, C.; GERARD, O.; COURTENS, L. J.; ANTON, M. Bull semen en vitro fertility after cryopreservation using egg yolk LDL: a comparison with Optidyl, a commercial egg yolk extender. Theriogenology, v. 61, p. $895-907,2004$

ARRUDA, R. P.; BALL, B. A.; GRAVANCE, C. G.; LIU, I. K. M. Avaliação dos efeitos de diluídores e crioprotetores para espermatozoides de garanhões utilizando análise computadorizada da motilidade (CASA) e citometria de fluxo. Acta Scientiae Veterinatiae, supl. 31, p. 228, 2003.

BAPTISTA SOBRINHO, C. A.; HATAMOTO, L. K; BARNABE, V. H.; NICHI, M.; OLIVEIRA, C. A. Efeitos do estresse de trabalho sobre parâmetros seminais de cães da raça Rottweiler. Brazilian Journal of Veterinary Research and Animal Science, v. 46, p. 280-287, 2009.

BLOM, E. The ultra-structure of some characteristic sperm defects and proposal a new classification of the Bull spermiogram. Nordisk Veterinaer Medicin, v. 25, n.7, p. 383-391, 1973.

CASTRO, A. C. N.; PACHECO, A.; PINHO, T. G.; GODIM, D.; SANTOS, M. R. Viabilidade do sêmen canino submetido a criopreservação com glicerol e etileno-glicol. Revista Brasileira de Ciência Veterinária, v. 14, n. 1, p. 20-25, 2007.

CONCANNON, P. W.; BATTISTA, M. Canine semen freezing and artificial insemination. In: KIRK: Current Veterinary Therapy: small animal practice. 10. ed. Philadelphia: W. B. Saunders, 1989. p. 1.247-1.259. 
CORMIER, N.; SIRARD, M. A.; BAILEY, J. L. Premature capacitation of bovine spermatozoa is initiated by cryopreservation. Journal of Andrology, v. 18, p. 461-468, 1996.

CUNHA, I. C. N.; LOPES, B. V. Estudo do processo de refrigeração do sêmen canino utilizando-se diluídores à base de leite e glicina-gema. Revista da Educação Continuada do CRMV-SP, v. 3, n. 1, p. 37-42, 2000.

CUNHA, I. C. N.; LOPES, B. V.; PAPA, F. O.; DETMANN, E. Estudo da viabilidade de um novo diluídor para a refrigeração do sêmen canino. Revista Brasileira de Reprodução Animal, v. 29, p. 174-178, 2005.

DIDION, B. A.; DOBRINSKY, J. R.; GILES, J. R.; GRAVES, C. N. Staining procedure to detect viability and the true acrosome reaction in spermatozoa of various species. Gamete Research, v. 22, p. 51-57, 1989.

ENGLAND, G. C. W. Cryopreservation of dog semen: a review. Journal of Reproduction and Fertility, v. 47, p. 243-255, 1993.

ENGLAND, G. C. W.; PONZIO, P. Comparison of the quality of frozen-thawed and cooled-re-warmed dog's semen. Theriogenology, v. 46, p. 165-171, 1996.

HATAMOTO, L. K.; BAPTISTA SOBRINHO, C. A.; NICHI, M.; BARNABE, V. H.; BARNABE, R. C.; CORTADA, C. N. M. Effects of dexamethasone treatment (to mimic stress) and Vitamin E oral supplementation on the spermiogram and on seminal plasma spontaneous lipi peroxidation and antioxidant enzyme activities in dogs. Theriogenology, v. 66, p. 1.610-1.614, 2006.

HOLT, W. V. Basics aspects of frozen storage of semen. Animal Reproduction Science, v. 62, p. 3-22, 2000.

HENRY, M.; NEVES, J. P. Manual para exame andrológico e avaliação de sêmen animal. 2. ed. CBRA: Belo Horizonte, 1998. 49 p.

IGUER-OUADA, M.; VERSTEGEN, J. P. Long-term conservation of chilled canine semen: effect of commercial and laboratory-prepared extenders. Theriogenology, v. 55, p. 671-684, 2001.

IVANOVA-KICHEVA, M. G.; BOBADOV, N.; SOMLEV, B. Cryopreservation of canine semen in pellets and in 5-ml aluminum tubes using three extenders. Theriogenology, v. 48, p. 1.343$1.349,1997$.

JEYENDRAN, R. S.; VAN DER VEM, H. H.; PEREZ-PELAEZ, $M$. et al. Development of an assay to asses the functional integrity of the human sperm membrane and its relationship to the other semen characteristics. Journal of Reproduction and Fertility, v. 70, p. 219-228, 1984.

KENNEY, R. M.; BERGMAN, R. V.; COOPER, W. L. Minimal contamination techniques for breeding mares: technique and preliminary findings. Proceedings of American Association Equine Practitioners, v. 21, p. 327-336, 1975.

KUMI-DIAKA, J. Subjecting canine semen to the hypo-osmotic test. Theriogenology, v. 39, p. 1.279-1.289, 1993.

MAXWELL, W. M. C.; SALAMON, S. Liquid storage of ram semen: a review. Reproduction, Fertility and Development, v. 5, p. 613-638, 1993.

MOUSSA, M.; MARTINET, V.; TRIMECHE, A; TAINTURIER, D.; ANTON, M. Low density lipoproteins extracted from hen egg yolk by an easy method: cryoprotective effect on frozen thawed Bull semen. Theriogenology, v. 57, p. 1.695-1.706, 2002.

PARKS, J. E.; GRAHAM, J. K. Effects of cryopreservation procedures on sperm membranes. Theriogenology, v. 38, n. 2, p. 209-222, 1992.

PHILLIPS, P. H.; LARDY, H. A. A. Yolk buffer pabulum for the preservation of bull semen. Journal of Dairy Science, v. 23, p. 399-404, 1993.

RIJSSELAERE, A.; VAN SOOM, D.; MAES, A.; DE KRUIF, A. Effect of centrifugation on in vitro survival of fresh diluted canine spermatozoa. Theriogenology, v. 57, p. 1.669-1.681, 2002.

ROTA, A.; STROM, B.; LINDE-FORSBERG, C. Effects of seminal plasma and three extenders on canine semen stored at $4{ }^{\circ} \mathrm{C}$. Theriogenology, v. 44, p. 885-900, 1995.

SILVA, A. R.; CARDOSO, R. C. S.; UCHOA, D. C.; SILVA, L. D. M. Efeitos das etapas de cripreservação sobre a qualidade do sêmen canino diluído em Tris. Revista Brasileira de Reprodução Animal, v. 25, n. 3, p. 474-475, 2001.

SILVA FILHO, J. M.; FONSECA, F. A.; PALHARES, M. S.; OLIVEIRA, H. N. Fertilidade do sêmen equino diluído, resfriado e transportado. Revista Brasileira de Zootecnia, v. 26, n. 6, p. 1.134-1.141, 1997.

SIRIVAIDYAPONG, S.; CHENG, F. P.; MARCS, A.; VOORHOUT, W. F.; BEVERS, M. M.; COLENBRANDER, B. Effect of sperm diluents on the acrosome reactions in canine sperm. Theriogenology, v. 53, p. 789-802, 2000.

TARTAGLIONE, C. M.; RITTA, M. N. Prognostic value of spermatic parameters as predictors of in vitro fertility of frozen-thawed bull semen. Theriogenology, v. 62, p. 1.245-1.252, 2004.

VANNUCCHI, C. I.; SATZINGER, S.; SANTOS, S. E. C. Avaliação seminal em cães. Clínica Veterinária, v. 3, n. 15, p. 22-26, 1998.

VERSTEGEN, J. P.; ONCLIN, K.; IGUER-OUADA, M. Longterm motility and fertility conservation of chilled canine semen 
using egg yolk added Tris-glucose extender: in vitro and in vivo studies. Theriogenology, v. 64, p. 720-733, 2005.
VISHWANATH, R.; SHANNON, P. Storage of bovine semen in liquid and frozen state. Animal Reproduction Science, v. 62, p. 23-53, 2000.

Protocolado em: 4 set. 2008. Aceito em: 18 jan. 2011. 